\title{
Study on the Guangdong-Hong Kong-Macao Greater Bay Area
}

\section{Qianwen Yu}

School of Economics, Jinan University, Guangzhou, China

Email: yqwbgzy@163.com

How to cite this paper: Yu, Q.W. (2019) Study on the Guangdong-Hong KongMacao Greater Bay Area. Modern Econo$m y, 10,586-599$.

https://doi.org/10.4236/me.2019.103040

Received: January 28, 2019

Accepted: February 26, 2019

Published: March 1, 2019

Copyright $\odot 2019$ by author(s) and Scientific Research Publishing Inc. This work is licensed under the Creative Commons Attribution International License (CC BY 4.0).

http://creativecommons.org/licenses/by/4.0/

\begin{abstract}
The formation of the urban agglomeration of Guangdong-Hong Kong-Macao Greater Bay Area is the result of the accumulation of reform and opening up in the past 40 years. It is the natural choice for China to move from policy opening to institutional opening, and is also the inevitable path from an export-oriented economy to an open economy. Studying regional economic competitiveness is conducive to people's understanding of the basic conditions and characteristics of regional economic development, and through the objective assessment of regional economy, to find problems and take countermeasures to promote the sustainable and healthy development of the regional economy. The characteristics and advantages of the Guangdong-Hong Kong-Macao Greater Bay Area, the difficulties and bottlenecks in the construction of the Guangdong-Hong Kong-Macao Greater Bay Area, conclusions and recommendations are carried out in a comprehensive analysis of the Guangdong-Hong Kong-Macao Greater Bay Area. Finally, based on the results, the proposed policy recommendations are proposed from three aspects: system, technology, industry and talents. Firstly, targeting the world's leading Bay Area, coordinating the development of the Guangdong-Hong Kong-Macao Greater Bay Area; secondly, enhancing investment in science and technology to create a "Bay of Innovation" in the Guangdong-Hong Kong-Macao Greater Bay Area; thirdly, coordinating industrial layout and industrial development. Finally, building up the Bay Areas of Talents by training and introducing, accumulating the global high-end talent resources.
\end{abstract}

\section{Keywords}

Bay Area, The Guangdong-Hong Kong-Macao Greater Bay Area, Policy Suggestion

\section{Introduction}

Since the mid-1990s, due to the tremendous changes in the international politi- 
cal economy, market globalization has been established, and the degree of economic globalization based on market globalization has deepened. In recent years, regional economic integration has continued to heat up. Therefore, as the main body of competition for a country or region, the basic geographical unit of the country participating in international competition, and the urban group of the main form, it plays an increasingly important role in determining the comprehensive competitiveness of the country.

In 2001, "Outline of the Tenth Five-Year Plan for National Economic and Social Development of the People's Republic of China" put forward that "we should focus on developing small towns, actively develop small and mediumsized cities, improve the functions of regional central cities, give full play to the radiation-driven role of large cities, and guide the orderly development of urban-intensive areas". This is the first time that China has proposed the concept of "urban dense areas" related to urban agglomerations. In the "Outline of the Eleventh Five-Year Plan for National Economic and Social Development of the People's Republic of China", the government adopted the concept of urban agglomeration, pointing out that "the development of urban agglomeration will be the main form of urbanization in China". By 2011, the "Outline of the Twelfth Five-Year Plan" clearly put forward "in accordance with the principles of overall planning, rational layout, perfect functions, taking the big as the small, following the objective law of honest development, relying on big cities, and taking small and medium-sized cities as the basis, gradually forming a group of cities with large radiation effects, promoting the coordination of large, medium and small cities and small towns development of".

As a highly open economic form agglomerated by the bay, the bay area has become a new growth pole of global economic development and a leader in industrial and technological change. The economy of the Bay Area is highly open, innovative, cooperative, livable and suitable for business. Shen Yong pointed out in The Formation Mechanism of Bay Area Economy and the Orientation of the Guangdong-Hong Kong-Macao Greater Bay. at present, there are about 58 Bay Areas in the world, which are distributed in about 36 countries. These Bay Areas concentrate more than $60 \%$ of the world's social wealth, $75 \%$ of the big cities, $70 \%$ of the capital and population. New York Bay Area, San Francisco Bay Area and Tokyo Bay Area are the representatives of the world's successful Bay Area.

As the fourth largest bay area after New York Bay Area, San Francisco Bay Area and Tokyo Bay Area, the Guangdong-Hong Kong-Macao Greater Bay is an important space carrier for China to build world-class urban agglomeration and participate in global competition.

Deepening the cooperation between Guangdong, Hong Kong and Macao is an important measure for the central government to unswervingly push forward the great cause of the "one country, two systems" policy and support the longterm prosperity and stability of Hong Kong and Macao. It is also an important task entrusted to the Guangdong by the central government. 
Premier Li Keqiang clearly stated in the 2017 Government Work Report that "we should promote the deepening cooperation between the Mainland and Hong Kong and Macao, study and formulate the development plan of the guangdong-Hong Kong-Macao Greater Bay Area, and play to the unique advantages of Hong Kong and Macao to enhance its position in national economic development and opening up. With the function, it means that the Guangdong-Hong Kong-Macao Greater Bay Area officially rose to the national strategy.

The formation of the Guangdong-Hong Kong-Macao Greater Bay is the result of the accumulation of reform and opening up in the past 40 years. It is the natural choice for Chinese society to move from policy opening to institutional opening. It is also the inevitable path from an export-oriented economy to an open economy. Constructing the urban agglomeration of Guangdong-Hong Kong-Macao Greater Bay is not only an intrinsic need for the economic, social and cultural development of the Guangdong, Hong Kong and Macao regions, but also an important exploration for the country to build a new open economic system with the help of Hong Kong and Macao international windows. It is also an important innovation for enriching and developing the practice of the "one country, two systems" policy. It is also an important innovation to give full play to the overall advantages of Hong Kong and Macao, inject new kinetic energy into Hong Kong and Macao's development, and enhance its leading role in the country's economic development and all-round opening. Therefore, the urban agglomeration of Guangdong-Hong Kong-Macao Greater Bay carries the country's multiple strategic functions. It is not only a rich, perfect and innovative development of the "one country, two systems" policy, but also a "test field" for China to explore participation in global governance and regional governance in the new era. Under the new era, China has provided new programs and demonstrations for global cross-border cooperation and economic and social governance.

\section{The Rise of Bay Area Economy}

With the development of information communication and transportation technology, and the reshaping of the world economic geography by economic globalization, large urban agglomerations have gradually replaced individual cities as the mainstay of regional competition, becoming the basic regional unit and supporting development of a country's participation in international division of labor and cooperation.

Based on the natural and geographical conditions of the Bay Area, and the development of developed port logistics, the Bay Area economy is a coastal type of regional economic form. The Bay Area economy is concentrated in the Bay and Prosperous because of the port. It has an open economic structure, a sound industrial chain, convenient port transportation, efficient resource allocation, strong agglomeration radiation function and developed international communication network. It's an important component of the economic map. As an important 
coastal economy, the Bay Area often plays an important leading role in the region and even the country.

At present, the typical international first-class Bay Area mainly includes the New York Bay Area, the San Francisco Bay Area and the Tokyo Bay Area. These three major Bay Areas are world-class financial centers, service centers, shipping centers and innovation centers. Among them, the New York Bay Area is a Bay Area with international capital agglomeration and logistics hubs. The headquarters of multinational corporations, financial institutions and exchanges are gathered. The San Francisco Bay Area is a knowledge-driven Bay Area with Silicon Valley as its typical model. It has more than 20 institutions of higher learning. The school and a large number of innovative enterprises; the Tokyo Bay Area is an industrial base type bay area based on the port group, with an annual throughput of more than 500 million tons and a total economic output of onethird of the country.

\section{Current Situation of Study about the Guangdong-Hong Kong-Macao Greater Bay}

With the advancement of globalization and urbanization, the region has become the main carrier of economic development, and the Bay Area, with its unique advantages, has great significance for global development. Li Lixun [1] pointed out that the Bay Area occupies an important growth polar position in driving global economic development and is the leader of scientific and technological innovation. Liu Yanxia [2] pointed out that the bay area is composed of a bay or several adjacent bays, harbours, surrounding islands and sea areas, ranging from 5 square kilometers to 1 million square kilometers, and is divided into four grades: super-large, large, medium and small. The bay area economy is based on the natural geographical conditions of the Bay area. It consists of many harbors and towns along the coastal ports, which constitute the harbor agglomeration area and urbanization space. Lin Xianyang [3] pointed out that the Bay Area economy is at the junction of macro and micro economy, coastal and inland economy. With its open economic structure, perfect industrial chain, convenient port transportation, efficient resource allocation, strong radiation function and developed international communication network, it has become an important engines for regional and even global economy. The Guangdong-Hong Kong-Macao Greater Bay Area is a hot regional concept at present. The important thing in the Guangdong-Hong Kong-Macao Greater Bay Area is not the "Bay Area" but the "Guangdong, Hong Kong and Macao", which emphasizes the expansion and deepening of the cooperative relationship among Guangdong, Hong Kong and Macao, maintaining the prosperity and stability of Hong Kong and Macao's economy, and enhancing the position of Guangdong, Hong Kong and Macao in national economic development and opening up. Qin Chenglin et al. [4] pointed out that the Guangdong-Hong Kong-Macao Greater Bay Area is a " $9+2$ " structure, which is exactly the same as the urban agglomeration of the Pearl River Delta in terms of composition. The change of name highlighted the qualitative 
change of the strategic mission of the urban agglomeration of the Guangdong-Hong Kong-Macao Greater Bay Area in China's economic development. Cai Chimeng [5] believed that the construction of the urban agglomeration in the Guangdong-Hong Kong-Macao Greater Bay Area is not only the inherent need of the regional economic, social and cultural development of Guangdong, Hong Kong and Macao, but also an important exploration for the state to build a new open economic system through the international window of Hong Kong and Macao. It is also an important innovation to enrich and develop the practice of "one country, two systems". It is a major measure to give full play to the advantages of Hong Kong and Macao, to inject new kinetic energy into Hong Kong and Macao's development, and to enhance its leading role in national economic development and all-round opening. At present, the Guangdong-Hong KongMacao Greater Bay Area has shown the embryonic form of the world first-class Bay Area Urban Agglomeration and the international free trade port, and will become a giant gateway hub of the "the Belt and Road" construction and a world-class economic platform and an international science and technology innovation center.

At present, the research on the Guangdong-Hong Kong-Macao Greater Bay Area is still mainly focused on conceptual analysis, international comparison, problem research and policy recommendations. The empirical research on the Guangdong-Hong Kong-Macao Greater Bay Area has just begun.

\section{Competitive Advantages and Bottlenecks of Urban Agglomerations in Guangdong-Hong Kong-Macao Greater Bay}

The urban agglomeration in Guangdong-Hong Kong-Macao Greater Bay Area consists of " $9+2$ " -9 cities in the Pearl River Delta, Hong Kong and Macao. It is located in the three economic circles of "Guang Fo Zhao", "Shen Guan Hui" and "Zhu Zhong Jiang", as well as in the deep integration area of Hong Kong and Macao, which are two major external window cities. It also has close contacts with the coastal areas of the Maritime Silk Road and the countries along the route. The basic advantages are obvious.

In 2016, the urban agglomeration of Guangdong-Hong Kong-Macao Greater Baycovers an area of more than 56,562 square kilometers, with a population of about 66 million and a total GDP of about 136 trillion US dollars. It has created about $12 \%$ of the total economic volume in the whole country with less than $0.6 \%$ of the land and $4.8 \%$ of the population in the whole country, and has become the thirteenth largest economy in the world. It has a strong momentum of development in the future. It is the pivotal growth pole of the national and even the world economy.

\subsection{Competitive Advantages}

The existing Bay areas in China include Hangzhou Bay Area, Bohai Bay Area, Beibu Bay, Jiaozhou Bay, Guangdong-Hong Kong-Macao Greater Bay. Regard- 
less of the Bay area, the overall level of development, or the degree of internal economic linkages, the urban agglomeration of Guangdong-Hong Kong-Macao Greater Bay has more open, efficient, clustering, network and other characteristics of world-class Bay areas.

\subsubsection{The Rapid Development of the Economy, the Urbanization Rate of} the Bay Area Cities Reached the Level of Developed Countries

The Guangdong-Hong Kong-Macao Greater Bay has made remarkable achievements in economic development by virtue of its open natural geographical advantages and export-oriented development model. Only in 2016, Guangzhou's GDP reached 1.95 trillion, accounting for $2.64 \%$ of GDP. The annual growth rate reached $7.99 \%$, exceeding the national average of $6.7 \%$; the proportion of tertiary industry in Hong Kong and Macao reached $80 \%$.

With the advancement of globalization and the implementation of China's reform and opening-up policy, the urbanization rate of the Guangdong-Hong Kong-Macao Greater Bay is also constantly improving. Among them, Hong Kong, Macao and Shenzhen have been completely urbanized. The urbanization rate of Zhaoqing is $46.08 \%$, less than $50 \%$.This strengthening of inter-regional links has broken administrative barriers and changed the situation of their own development planning to a certain extent. Each region has begun to explore the development path of coordination and cooperation, laying a foundation for the enhancement of competitiveness of the Guangdong-Hong Kong-Macao Great Bay Area (see Table 1).

\subsubsection{Superior Economic Location Advantage and High Degree of Openness}

First of all, the natural environment advantage of the Guangdong-Hong Kong-Macao Great Bay Area is highlighted. On the one hand, the Guangdong-Hong Kong-Macao Great Bay Area is located in the estuary delta, with

Table 1. The urbanization rate of the Guangdong-Hong Kong-Macao greater bay (\%).

\begin{tabular}{cccc}
\hline & 2000 & 2010 & 2016 \\
\hline Guangzhou & 83.79 & 83.78 & 86.06 \\
Shenzhen & 92.46 & 100 & 100 \\
Zhuhai & 85.48 & 87.65 & 88.80 \\
Foshan & 75.06 & 94.09 & 94.95 \\
Huizhou & 51.66 & 61.84 & 69.05 \\
Dongguan & 60.04 & 88.46 & 88.68 \\
Zhongshan & 60.67 & 87.82 & 88.20 \\
Jiangmen & 47.08 & 62.30 & 65.06 \\
Zhaoqing & 32.52 & 42.39 & 46.08 \\
Hong Kong & 100 & 100 & 100 \\
Macao & 100 & 100 & 100 \\
\hline
\end{tabular}

Source: "Statistical Yearbook of Guangdong Province 2016". 
excellent climatic conditions, dense river networks and relatively developed agriculture. On the other hand, the Guangdong-Hong Kong-Macao Great Bay Area has the characteristics of marine economy. The major cities in the interior are located in traffic fortresses. The effect of the joint channel between the seaport and the airport is strong.

Secondly, the export-oriented development model of Guangdong-Hong Kong-Macao Great Bay Area makes it integrate into the global economic system. Compared with other regions, it is early and deep. There are developed port cities such as Guangzhou, Shenzhen and two world window cities, Hong Kong and Macao, which are not only important ports for opening up to the outside world, but also important node connecting the domestic market and the international market. For example, in 2016, nine cities in the mainland alone accounted for one fifth of the total amount of foreign capital used in the country. Zhangyu et al. (2017) made an empirical study on the economic openness of the Guangdong-Hong Kong-Macao Great Bay Area from five aspects: total economic volume, product market openness, capital market openness, population openness and export-oriented infrastructure openness. The results showed that the population openness measured by the proportion of immigrants, the Guangdong-Hong Kong-Macau Great Bay are far below the world-class Bay Area of New York, Tokyo and San Francisco. The openness of product market and capital market is much higher than that of the three bays, and the openness of product market is higher than that of capital market. In addition, infrastructure conditions also lead the three major bays, laying the foundation for further enhancing their openness and competitiveness.

\subsubsection{Strong Economic Strength, Strong Development Speed and Scale}

The overall economy of the Guangdong-Hong Kong-Macao Great Bay Area has developed rapidly. The economic aggregate has more than tripled during the fifteen years from 2000 to 2015, making Guangdong-Hong Kong-Macao Great Bay Area an important indicator of China's economic development. In 2016, the total GDP of the Guangdong-Hong Kong-Macao Great Bay Area reached 9.18 trillion, accounting for $12 \%$ of the national GDP; the per capita GDP was 145,532 yuan, far exceeding the national average of 53,935 yuan.

\subsubsection{Complete Industrial System and High Degree of Openness}

Drawing on the division of the world Bay area between the East and the west, we first divide the Guangdong-Hong Kong-Macao Great Bay Area into three parts: the east coast of the Bay Area-Guangzhou, Foshan, Zhuhai, Zhongshan, Jiangmen and Zhaoqing; the west coast of the Bay Area-Shenzhen, Dongguan, Huizhou; Hong Kong and Macao.

The industrial structure of the Guangdong-Hong Kong-Macao Great Bay Area is relatively balanced. In terms of finance, Hong Kong is the third largest financial center in the world, and Shenzhen is the domestic financial center. In 2016, Hong Kong ranked 3rd in the Global Financial Center Index, Shenzhen ranked 22nd., and Guangzhou ranked No. 37 for the first time. In terms of in- 
dustry, the industrial belt of the Guangdong-Hong Kong-Macao Great Bay Area is divided into three parts: the knowledge-intensive industrial belt on the east coast of the Bay Area, the technology-intensive industrial belt on the west coast of the Bay Area, and the coastal eco-environmental protection heavy industry belt. The eastern coast is dominated by modern services, high-tech industries and strategic emerging industries, such as finance, information services, new materials, etc. The West Bank is dominated by modern service industry, equipment manufacturing industry and superior traditional industries, such as modern logistics, household appliances, metal products, etc. Coastal eco-environmental heavy chemical industry belt includes Huizhou, Shenzhen, Zhuhai and Jiangmen coastal areas, mainly with advanced manufacturing industries, such as petrochemical industry, biomedicine and so on.

Since the reform and opening-up in 1978, Guangdong has adopted an export-oriented industrial development strategy. The cooperation between Guangdong and Hong Kong and Macao has gone through the process from "after former shop factory" pattern-the vertical division of manufacturing industry to the horizontal integration of industries with the liberalization of trade in services as the core, and then to the current process of region economy as the carrier to participate in the international middle and high-end competition. During this period, the advantages of Guangdong, Hong Kong and Macao complement each other, industrial transfer and industrial restructuring and upgrading go on at the same time, the degree of opening to the outside world continues to improve, and the overall international competitiveness has been enhanced.

\subsubsection{Strong Foundation of Innovative Economy}

The Guangdong-Hong Kong-Macao Great Bay Area not only rely on the strong manufacturing industry of the Pearl River Delta, but also to meet the needs of industrial expansion. There are many institutions of higher learning and research institutions, with abundant talent reserves in the Guangdong-Hong Kong-Macao Great Bay Area. There are many headquarters, R \& D centers of multinational corporations, as well as various national innovation institutions and sizes in the Guangdong-Hong Kong-Macao Great Bay Area. Specifically, the Guangdong-Hong Kong-Macao Great Bay Area has one national-level independent innovation demonstration zone, three national innovative cities, and 43 national key laboratories. And a variety of colleges and professional institutions gather, such as the University of Hong Kong, University of Macau, Sun Yat-sen University, the Chinese University of Hong Kong, the Hong Kong University of Science and Technology, South China University of Technology, etc., human resources reserves are very rich, and it is a well-known intelligence-intensive area and talent highland.

Taking invention patents as an example, the total number of invention patents in the Guangdong-Hong Kong-Macao Great Bay Area has increased steadily over the years, from 61,764 in 2012 to 193,712 in 2016, especially in 2015, with a growth rate of nearly $50 \%$. 


\subsubsection{Interconnected Infrastructure Such as Ports, Airports and Bridges,} and High-Speed Rail Are Highly Developed

At present, the Guangdong-Hong Kong-Macao Great Bay Area has excellent ports such as Hong Kong, Guangzhou, Shenzhen, Zhuhai, Zhongshan and Nansha; five main airports in Hong Kong, Macao, Guangzhou, Shenzhen and Zhuhai; the total mileage of expressways is 7673 kilometers; the total mileage of Railways is 5500 kilometers; the total mileage of intercity rails is 1430 kilometers; and the main bridge project of Hong Kong-Zhuhai-Macao Bridge, and it will be completed smoothly in 2016; Shenzhen-Zhongshan Passage is expected to open to traffic by the end of 2024; Humen Second Bridge is also expected to be completed by 2019; and Ganzhou-Shenzhen, Guangzhou-Shantou High-speed Railway has begun construction.

Based on the developed material network (such as transportation network) and intangible network (such as production network), the Guangdong-Hong Kong-Macao Great Bay Area links the inter cities and urban agglomerations through the network of people flow, logistics, capital flow and information flow in the global production relations network to seek coordinated development.

\subsection{Bottlenecks}

\subsubsection{The Division of Labor Is Similar, and the Phenomenon of Industrial Isomorphism is Prominent}

Due to the different economic systems and laws between Hong Kong, Macao and Guangdong, they belong to three different economies and customs zones. The internal market of Guangdong, Hong Kong and Macao in the Great Bay Area is divided, and the flow of people, logistics, information and capital cannot be completely free. All these lead to the same division of labor in the Bay Area and the prominent industrial isomorphism.

Lin Xianyang (2017) measured the similarity of industrial structure in the Guangdong-Hong Kong-Macao Great Bay Area in 2016 (see Table 2). The results show that the similarity of major industries in the Guangdong-Hong Kong-Macao Great Bay Area, except jiangmen, is high, especially in Shenzhen,

Table 2. Industrial structure similarity coefficient of the Guangdong-Hong Kong-Macao great bay area (2015).

\begin{tabular}{|c|c|c|c|c|c|c|c|c|c|}
\hline CITY & Guagzhou & Shenzhen & Zhuhai & Foshan & Huizhou & Dongguan & Zhongshan & Jiangmen & Zhaoqing \\
\hline Guangzhou & 1 & & & & & & & & \\
\hline Shenzhen & 0.518 & 1 & & & & & & & \\
\hline Zhuhai & 0.612 & 0.822 & 1 & & & & & & \\
\hline Foshan & 0.751 & 0.369 & 0.750 & 1 & & & & & \\
\hline Huizhou & 0.435 & 0.986 & 0.768 & 0.413 & 1 & & & & \\
\hline Dongguan & 0.574 & 0.957 & 0.854 & 0.496 & 0.945 & 1 & & & \\
\hline Zhongshan & 0.735 & 0.747 & 0.886 & 0.812 & 0.756 & 0.854 & 1 & & \\
\hline Jiangmen & 0.268 & 0.156 & 0.165 & 0.658 & 0.123 & 0.165 & 0.278 & 1 & \\
\hline Zhaoqiqng & 0.705 & 0.667 & 0.676 & 0.655 & 0. 599 & 0.667 & 0.781 & 0.250 & 1 \\
\hline
\end{tabular}

Data Source: "Study on Economic Integration of Urban Agglomeration in the Guangdong-Hong Kong-Macao Great Bay Area". 
Huizhou and Dongguan. The similarity coefficient reaches 0.986 at the highest and 0.945 at the lowest, and the phenomenon of industrial isomorphism is serious.

\subsubsection{Disordered Agglomeration and Competition among Cities in the Guangdong-Hong Kong-Macao Great Bay Area Are Overt}

At present, the Guangdong-Hong Kong-Macao Great Bay Area has not yet realized the free flow of people, logistics, information flow and capital chain. Local enterprises are still rushing to OEM, the scale and brand are subject to multinational companies, and enterprises are at the low end of the value chain. The value is low and local governments have failed to give full play to their respective advantages to enhance the overall competitiveness of the Guangdong-Hong Kong-Macao Great Bay Area.

Globalization has made the world today connected in an "interconnected" way. The development of countries or regions is no longer independent, but interacts with each other, which makes the development of countries or regions open. Moreover, the urbanization rate of the Guangdong-Hong Kong-Macao Great Bay Area has been increasing, and the inter-regional links have been strengthened. All of these have broken administrative barriers to a certain extent and changed the situation of development planning. However, at present, the construction of the Guangdong-Hong Kong-Macao Great Bay Area lacks toplevel design. Industrial development, functional division of labor, infrastructure, cultural construction and ecological environment are lack of comprehensive coordination mechanism, and driven by the government performance appraisal system, cities focus on their own development, leading to repetitive construction and disorderly competition.

\subsubsection{Infrastructure Interconnection of Urban Agglomeration in the Guangdong-Hong Kong-Macao Great Bay Area Is Low}

The Guangdong-Hong Kong-Macao Great Bay Area have developed transportation networks. The main infrastructures such as ports, airports, bridges and high-speed railways are complete, and a close inter-city transportation network has been formed in the Guangdong-Hong Kong-Macao Great Bay Area. However, there is no unified planning for the construction of transportation infrastructure in the Guangdong-Hong Kong-Macao Great Bay Area, or a sense of cooperation in coordination and coordination. There is no effective connection between various modes of transportation in the region.

The efficient allocation of production factors depends on the efficient transportation network. Due to the imperfect transportation network, the infrastructure of water and electricity within the Bay Area is basically in a state of division, and the overall optimal allocation is not realized.

\subsubsection{The Heterogeneity of "One Country, Two Systems" Policy, Three Tariffs and Three Legal Systems Has Become an Important Obstacle to the Cross-Border Integration of Tariffs, Laws and Institutional Mechanisms}

Guangdong, Hong Kong and Macao are divided into three different economies 
and customs zones, and the legal system is also different, which makes the goods, labor, technology, capital and other factors in the Bay Area unable to flow freely among the three markets, and there is border management. The mainland's external tariff level, factor circulation openness and legal system cannot be consistent with Hong Kong and Macao in the short term. How to break through in the future depends not only on the degree of openness and speed of the mainland, but also on the breakthrough in institutional innovation and crossborder management model in the Guangdong-Hong Kong-Macao Great Bay Area.

\section{Policy Suggestion}

\subsection{To Coordinate the Development of Guangdong, Hong Kong and Macao Bay Area According to the World's Leading Bay Area}

The economic development gap in the Guangdong-Hong Kong-Macao Great Bay Area is large, which is not conducive to the economic development of the whole Bay Area. Therefore, we should do a good job in the "top-level design" of the Guangdong-Hong Kong-Macao Great Bay Area. On the basis of the joint conference system, the central, Guangdong, Hong Kong and Macao quadripartite cross-regional administrative organs will be established, and they will be immobilized and permanently established to actively manage the Guangdong-Hong Kong-Macao Great Bay Area. Based on the international first-class Bay Area as a standard, their successful experiences, including industrial layout and functional structure, and overall infrastructure regulations, are worth learning and absorbing.

\subsection{Enhancing Science and Technology Investment and Creating "Bay of Innovation" in the Guangdong-Hong Kong-Macao Great Bay Area}

Globally, the Bay Area is no exception to the "Bay of Innovation", with a high concentration of all kinds of innovative resources. Apple, Google, Intel and many other global technology giants are clustered in San Francisco Bay Area. Tokyo Bay Area alone has gathered about a quarter of 500 private research institutes. In the Bay Area, there are 60 headquarters of the world's top 500 enterprises. Top universities such as Tokyo University, Stanford University, New York University and Princeton University have become the "wisdom springs" of the three Bay Areas.

The Guangdong-Hong Kong-Macao Great Bay Area, which has a fairly complete high-tech industry chain, is expected to become one of the most influential science and technology innovation centers in the world. Located in four of the world's 100 universities, Hong Kong has become the first overseas innovation center of the Massachusetts Institute of Technology in the United States.

Therefore, Shenzhen's innovative advantages should be combined with the strong manufacturing advantages of other cities in the Pearl River Delta to acce- 
lerate the integration of Hong Kong, Macao and overseas high-end resources, especially overseas Chinese high-end scientific and technological resources. We will further strengthen investment in science and technology and strive to reach the present level of Shenzhen in 2030, i.e. $4.32 \%$ in $\mathrm{R} \& \mathrm{D}$ investment and $60 \%$ in PCT international patent applications. We will also focus on Guangzhou High-tech Zone and Shenzhen High-tech Zone, Dongguan, Zhuhai High-tech Zone, Science City and Pazhou Internet Innovation Cluster Zone, and build a strategic source and will industrial base for cutting-edge scientific and technological achievements in the world, build a good science and technology innovation corridor in Guangzhou, and create a "South China Silicon Valley".

\subsection{Coordinating Industrial Distribution and Industrial Development}

From the statistical data, it can be seen that except for the tertiary industry as the dominant industry structure in Hong Kong and Macao, the urban agglomeration in the Guangdong-Hong Kong-Macao Great Bay Area is in the late stage of industrialization on the whole, and the law of industrial development shows that the development of tertiary industry, including producer services, is an important condition to promote its sustainable economic development. The urban agglomeration of Guangdong-Hong Kong-Macao Great Bay Area should start from the aspects of policy environment and supporting measures to speed up the development of modern service industry and cultivate modern industrial system. At the same time, we will vigorously develop the marine economy in the Guangdong-Hong Kong-Macao Great Bay Area. The South China Sea, where the Guangdong-Hong Kong-Macao Great Bay Area is located, is a special sea area with the most abundant marine resources and the most dense ocean-going routes for international trade. We should adhere to the concept of integration of land and sea and overall planning of land and sea, innovate the marine economic development planning of marine resources development, marine economic construction, marine route development and marine ecological protection in the Guangdong-Hong Kong-Macao Great Bay Area, construct a public service platform serving the open and cooperative development of marine economy in the Guangdong-Hong Kong-Macao Great Bay Area, and make full use of the Guangdong-Hong Kong-Macao Great Bay Area-financial advantages provide financial support for the development of marine economy, accelerate the exploration and development of combustible ice, seabed oil, natural gas and other deep-sea mineral deposits in the South China Sea, speed up the construction of marine strategic emerging industries and port-vicinity industries, and vigorously speed up the development of marine economic zones in the Guangdong-Hong Kong-Macao Great Bay Area and marine economy in the South China Sea.

Secondly, we should establish government assessment and fiscal and taxation policies that are suitable for the main functional areas of the Guangdong-Hong Kong-Macao Great Bay Area, guide the development of future industries rationally, realize the flexible distribution of industries, and form a new industrial divi- 
sion system and industrial chain. Specifically speaking, it is to t establish a center of industrial transfer and complementarity with Hong Kong, Guangzhou, Foshan, Shenzhen, Huizhou and Zhuhai, highlight Hong Kong's advantages in finance, information, logistics, talent and mature market awareness, and integrate it with the mainland area organically to take advantage of the differences in industrial development between the East and the West, to form an efficient industrial chain and industrial structure and build a good industrial ecology.

Finally, we should promote the development of industrial parks in the Guangdong-Hong Kong-Macao Great Bay Area. We should establish traditional industrial transfer parks to promote the industrial transformation and upgrading of the Guangdong-Hong Kong-Macao Great Bay Area; establish industrial park alliance organizations in the Guangdong-Hong Kong-Macao Great Bay Area, give priority to supporting the cultivation of superior industries, construction of superior projects, scientific and technological innovation, research and development of new products, and give full play to the development potential of later cities such as Jiangmen and Zhaoqing. By promoting the cross-regional agglomeration and coordinated development of industries, higher-level industrial chains and clusters can be formed so as to participate in global competition at a higher level.

\subsection{Draw up the "the Guangdong-Hong Kong-Macao Great Bay Area Talent Plan" and Build up the Bay Areas of Talents by Training and Introducing, Accumulating the Global High-End Talent Resources}

To build core talents in the Guangdong-Hong Kong-Macao Great Bay Area, a large number of high-end talents need to be introduced and trained. Yasushi Nagasaki, chairman of Japan's Sun Economic Council, believes that Japan's successful experience in building the Greater Tokyo Bay Area is "immigration", through population mobility, talent introduction and personnel training. We should formulate and implement the "Bay Area Talent Plan", and use Hong Kong's advantages as a global talent center for Chinese integrating global resources and introducing overseas Chinese talents. By attracting foreign talents to Hong Kong or Shenzhen, we will set up cooperative innovation centers such as robots and artificial intelligence to train large-scale robots and artificial intelligence technicians. The core of training talents is to build a new type of university. We should make use of the existing academic advantages of Hong Kong and Guangdong in university education and personnel training to accelerate the construction of a large number of high-level universities with world-class or internationally renowned high-level universities, making it an innovative university that focuses on cultivating innovative entrepreneurial culture and talents the Guangdong-Hong Kong-Macao Great Bay Area should cultivate and build an atmosphere of tolerance of failure \& encouragement innovation, cultivate an innovative ecology and environment of integration of production, teaching and research- "Plant up the parasol tree, lead to come to gold Phoenix". 
Under the guidance of the government and the above-mentioned policies, the Guangdong-Hong Kong-Macao Great Bay Area will be built into a super-bay area comparable to the three major bays.

In addition, this paper focuses on theoretical research and does not establish a model for empirical research, which is also the direction of future efforts of the article.

\section{Conflicts of Interest}

The author declares no conflicts of interest regarding the publication of this paper.

\section{References}

[1] Li, L.X. (2017) Some Thoughts on the Guangdong-Hong Kong-Macao Great Bay Area. Tropical Geography, 37.

[2] Liu, Y.X. (2014) Research on Economic Development of Bay Area at Home and Abroad. City Insight, 3.

[3] Lin, X.Y. (2017) Study on Economic Integration of Urban Agglomeration in the Guangdong-Hong Kong-Macao Great Bay Area. Guangdong People’s Publishing House, Guangzhou.

[4] Qin, C.L., Liu, L.L. and Qin, W.H. (2017) Strategic Consideration on the Development of Urban Agglomeration in the Guangdong-Hong Kong-Macao Great Bay Area. Regional Economic Review, 5.

[5] Cai, C.M. (2017) Strategic Significance and Realistic Chanllenges of Urban Agglomeration Construction in the Guangdong-Hong Kong-Macao Great Bay Area. Guangdong Social Science, 4. 